\title{
Two sides of the same coin? The Energy Transition Potential in Global North and Global South Countries
}

\section{Schrutir Jain}

University of Twente: Universiteit Twente

Maarten Arentsen ( $\nabla$ m.j.arentsen@utwente.nl)

CSTM University of Twentwe, 7500 AE Enschede, The Netherlands https://orcid.org/0000-0001-81861950

Albert Molderink

University of Twente: Universiteit Twente

Original article

Keywords: Climate change, renewable energy transition, global north, global south

Posted Date: May 13th, 2021

DOl: https://doi.org/10.21203/rs.3.rs-482946/v1

License: (c) (1) This work is licensed under a Creative Commons Attribution 4.0 International License.

Read Full License 


\title{
Two sides of the same coin? The Energy Transition Potential in Global North and Global South Countries
}

\author{
University of Twente, The Netherlands \\ Schrutir Jain, schrutir.jain@gmail.com \\ Maarten J. Arentsen, m.j.arentsen@utwente.nl \\ Albert Molderink¹ a.molderink@utwente.nl \\ Correspondence to m.j.arentsen@utwente.nl
}

\section{Abstract \\ Background}

Climatic changes have made transition to renewable energy essential. However, energy transition in the globalized world is challenged with diversification in culture, economic prowess, social development, and state structure. The global negotiations are always tough, among others, due to the split between the Global North (GN) and Global South (GS) countries. At the same time, the debates on how to deal with the inequalities in climate mitigation potential veils a thus far hardly acknowledged difference in energy transition potential and impact in the GN and GS countries. This paper, therefore, aims to contribute to bridging this knowledge gap by making a systematic comparative assessment of energy transition potential in the GN and GS with two regions as example cases.

\section{Method}

We used EnergyPLAN, the widely used energy model tool developed by the Sustainable Energy Planning Research Group at Aalborg University, Denmark. EnergyPLAN models a smart energy system, while analysing the energy balance, resource utilization, techno-economic cost, and carbon emission of the overall energy system (EnergyPLAN, 2017). The analysis has been conducted under the assumption of energy neutrality in 2050 with priority for renewable based technologies, minimalization of electricity import and export and optimizing fuel balances (EnergyPLAN, 2017).

\footnotetext{
${ }^{1}$ University of Twente
} 


\section{Results}

We analysed and compared energy scenarios in two regions in the world: Overijssel representing the GN countries and Matura representing the GS south countries. Both regions are similar in economic activities, but differ in demography and economic development. We analysed and compared the current energy system in both regions and two development scenarios towards 2050: the BAU scenario and the zero emission scenario. Despite the differences in starting position, the energy systems in both regions move towards each other in the longer term, but change pattern and costs differ.

\section{Conclusion}

In both regions bioresources are the dominant renewable resource in an locally determined energy resource portfolio. However, the costs of getting into this longer term position are significantly higher in Matura than in Overijssel, whereas the general economic potential, as it looks in 2020, is worse in Matura. Our analysis therefore indicates that a renewable energy transition in the longer term can result in zero emission systems in both GN and GS countries, but with substantial differences in costs.

\section{Introduction}

Under the COP 21 Paris Agreement, countries need to make a transition to renewable and sustainable energy away from fossil fuels. The negotiations are always tough, among others, due to the split between the Global North $(G N)$ and Global South (GS) countries. The Global North, roughly referring to the industrialized world with stable states, well-developed economies and high quality of life (Eriksen, 2015) are focused on green agendas (Kemmler \& Spreng, 2007), i.e., the sustainability of environment, resource degradation and waste aggregation (Savage, 2006). On the other hand, the Global South roughly referring to developing and under-developed countries, emphasize brown agendas. This includes poverty, lack of food, poor education and healthcare, human and civil rights abuse, ethnic and religious violence (Ming'ate, 2015), pollutants, waste hazards, lack of infrastructure and unequal distribution of resources and wealth. These developmental issues for the GS, are rendered as social issues for the GN (Collins, 2000). Moreover, when analysed empirically, we observe this division with low level of productivity, increasing population size, agricultural production rate and inadequate power in international relations from the GS (Odeh, 2010).

As a result, the climate mitigation potential of both country blocks appears to be quite different. At the same time, the debates on how to deal with the inequalities in climate mitigation potential veils a 
thus far hardly acknowledged difference in energy transition potential and impact in the GN and GS countries. This is only indirectly debated as a development issue with respect to GS countries, saying that these countries need room for economic development to be able to invest structurally in climate mitigation. With respect to energy this means transforming the current dominance of fossils in energy production and consumption into a renewable one. What is less known in this transitional debate is the actual potential of countries to change its current energy system into a renewable one. Wind, sun, water and bioresources are considered as the renewable resources for energy production and consumption and to date only Global North countries and China have been successful in increasing the share of these renewables in energy production.

Several international organizations like the IEA or IRENA publish country wide scenarios with respect to renewable potential but how these scenarios translate to the regional arena's where the energy transition is supposed to be implemented is less know. This paper, therefore, aims to contribute to bridging this knowledge gap by making a systematic comparative assessment of energy transition in the GN and GS with two regions as example cases. Our research is guided by the following research question: What are the differences and similarities in the regional sustainable energy transition in the Global North and Global South, with the region Overijssel in the Netherlands and the region Matura in India as illustrative examples?

The question is answered as follow. The section of the paper analyses and compares the energy transition dynamics in the GN and GS countries based on literature. The general idea of energy transition in both parts of the globe are specified for two example regions: Overijssel in the Netherlands representing the GN and Matura in India representing the GS. The energy transition potential in both regions is systematically analysed and compared with the help of the energy transition scenario. The scenarios are modelled on the basis of the economic activities, societal development, regulations, and technology availability and simulated on EnergyPLAN software. The scenarios allow to systematically compare the energy potential in both regions in the world and to answer the central research question.

\section{Global North and Global South: Differences in Energy Context}

The term Global North and Global South was introduced during the post-cold war era to signify the developed and the developing or under-developed countries globally. The developed countries in the world were kept in the frame of GN as they were majorly from the northern hemisphere but also had 
countries like Australia and New Zealand from the South. While the under-developed and developing countries were placed in the bracket of GS. This distinction is not purely based on geographical locations and neither on income, GDP (Gross Domestic Production) or HDI (Human Development Index). Instead, it shows a difference in the public sector, state organization, economic development, industrial development, social development, and equal share of resources between the globalized world (60 Second guide to the Global North/South Divide).

These differences can also be witnessed in the context of energy consumed, possibilities to sustain secure energy supply and variation in carbon emissions between GN and GS countries. Historically, human progression and state development has been linked with the availability and consumption of energy. In the last two centuries we have observed exponential rise in energy consumption due to industrial development (Sørensen, 2012). This increase in consumption has been unequal among countries (Arto, Capellan-Perez, Lago, Bueno, \& Bermejo, 2016) and between different social classes within the same state.

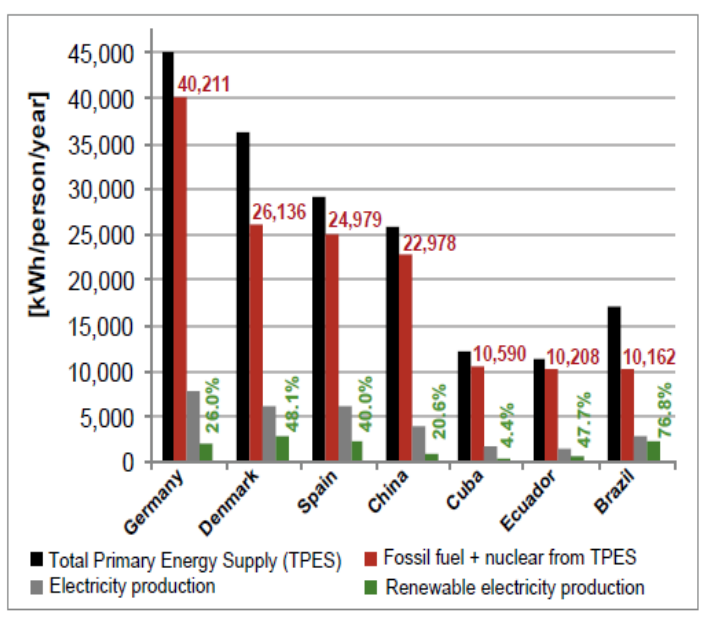

Figure 1: Primary Energy Supply per person every year in different countries signifying the differences in the GN and $G S$.
As we observe in the figure 1 a considerable difference in the total energy supply per person per year between the GN countries like Denmark and Germany and the GS countries like Cuba and China. This can be related with industrialization and security of supply in the developed world. On the other hand, when we interlink the energy supplied with equivalent carbon emission per person per year between these countries in figure 2, we observe a similar difference with the GN having a higher share of emission. 
However, we witness a decline in the emissions in figure 2 for Germany and Denmark, while increase in emissions in China, Brazil and Ecuador signifying a probable hidden energy flows (HEF). The ecological debt with these HEF, impacts the society and environment in the GS (Akizu, et al., 2017). Consequently, the emissions globally remain the approximately the same.

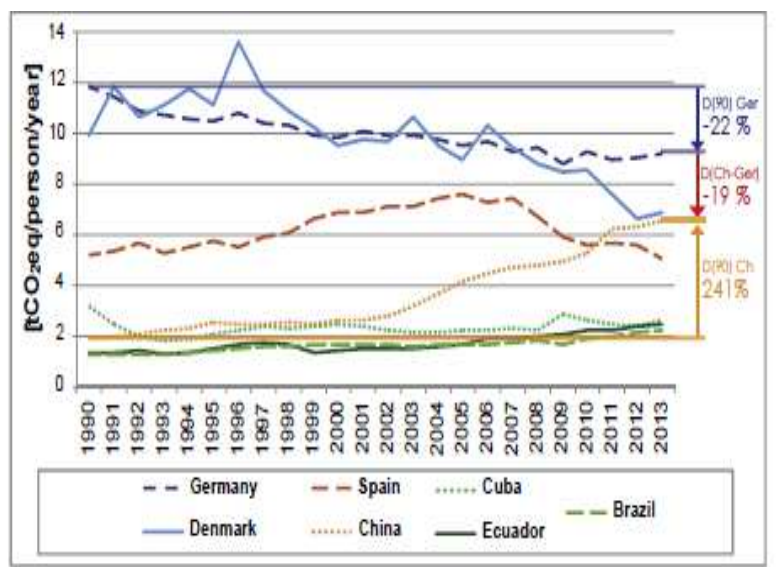

In addition to that, the distinction in the globalized world is also observed on the interpretation of

Figure 2: CO2eq emission from fuel consumption for the energy supply of globalized countries. energy poverty. In the GN, energy poverty is related to the implications of affordability of the primary energy requirements (Sen, 2014). Higher prices for energy specifically thermal comfort in the GN can make it unaffordable for local public leading to poor health or reduced expenses to meet other needs of a household (Day, Walker, \& Simcock, 2016).

For the GS, energy poverty holds a different explanation as the states are unable to provide reliable energy services due to lack of the energy infrastructure (Sen, 2014). Billions of people do not have access to energy, clean water, safety and food security and the focal point is to get access to energy to provide these amenities (Day, Walker, \& Simcock, 2016). Often the local households in the GS are dependent on raw biomass and fossil fuels for daily activities. Utilizing these resources generates pollutants that has a more profound effect on the health of women and children (Bruce, Perez-Padilla, \& Albalak, 2000). Additionally, collecting these resources by personals in the rural areas is timeconsuming that does not result in knowledge and income and further reduces their productivity level (Day, Walker, \& Simcock, 2016).

The sustainable energy transition can be at the forefront of overall development in the globalized world for their respective green and brown agendas. Through the medium of transformation to renewable energy the GN can optimize their ways of energy consumption through innovation without compromising the economic resilience and quality of life (Arto, Capellan-Perez, Lago, Bueno, \& Bermejo, 2016). Thus, reducing their equivalent carbon emissions and enhancing environmental and resource sustainability. On the other hand, the GS can make a switch to renewable energy improving their energy infrastructure through distributed generation system and improve their economic growth and standard of living for their citizens. 
However, transition in the energy system is challenged by geographical locations, demography, economics and politics along with culture and historical traditions (Laurie, Andolina, \& Radcliffe, 2005). The GS presents challenges to energy transition with inefficient energy data collection and the energy acquisition illegally through black market (Day, Walker, \& Simcock, 2016). Additionally, the implementation of renewable energy in the GS is deterred by corporate greed. For instance, the hydroelectricity plant in Brazil occupied the land from the locals and transferred it to the corporates. The prices of the energy generated remains high and the wealth generated is kept by the owners, while the workers are exploited, and no benefits are transferred to the displaced locals.

On the other hand, the energy transition in the GN presents different challenges. The data availability and studies provide support to technological innovations and transition. However, there are limitations in the process through excessive consumption, strict policies, and societal approval. For instance, the European Union regulates the use of land for bioresources and the Dutch government imposes similar regulations on cattle farmers and manure disposal. Another example to present difficulty in societal approval is the case of NIMBY (not in my backyard), a phrase used by the locals to avoid having wind turbines and bioenergy systems near their houses.

Further, the distinction can also be observed with the implementation of sustainable energy technology in the globalized world. The regions in the GN are more lenient towards a bottom-up approach or a democratic and social awareness approach, which are beneficial due to high rate of education and socio-economic equality. Meanwhile, the GS would be more lenient toward the top-down approach due to poverty, low literacy rates and inequality. Although, more developed Global South states also have an option to imply a democratic and social awareness approach.

Energy development is a wholly relative and context-dependent concept with all the regions in the globalized world share the spatial imbalances in geographical concentration related to economic growth, societal development and cultural values (Pike, Rodríguez-Pose, \& Tomaney, 2014). It is challenging to integrate a single transition model that reduces emissions while supporting the economic growth, as multiple social processes will have a different preview from diverse disciplines (De Paula \& Dymski, 2005). The current techniques and plans are formulated for the GN, while there is a minimal study on energy transition in GS. The ideas of sustainable development in the GN will not work in the GS (Rana, 2009).

\section{Methodology}


To present the empirical results for the differences and similarities in sustainable energy transition between the Global North and South, two regions from the globalized world are examined as a case study. The GN is represented by the Dutch province of Overijssel and the GS is represented by the Indian region Mathura.

We used EnergyPLAN, the widely used energy model tool developed by the Sustainable Energy Planning Research Group at Aalborg University, Denmark. EnergyPLAN models a smart energy system, while analysing the energy balance, resource utilization, techno-economic cost, and carbon emission of the overall energy system (EnergyPLAN, 2017). The analysis has been conducted under the assumption of energy neutrality in 2050 with priority for renewable based technologies, minimalization of electricity import and export and optimizing fuel balances (EnergyPLAN, 2017). The data requisites of EnergyPLAN are high which resulted in quite some missing values for Mathura and to a lesser degree for Overijssel. The missing data for Mathura have been indirectly gathered from governmental agencies and by extrapolating several available statistics like monthly electricity data for Mathura procured from Dakshinanchal Vidyut Vitran Nigam Limited (DNVVNL) (Appendix A).

Moreover, for both regions the predictive energy data for the year 2050 have been extrapolated by energy reports of the Netherlands and India and deduced for the regions based on historical data (Overijssel) and base load scenario (Mathura). The Appendix A explains in more detail the data used in the analysis. ${ }^{2}$

The energy model simulations are conducted for three scenarios namely the reference scenario for the current energy system, the business-as-usual scenario for the year 2050 for autonomous development of the current energy system and the energy transition scenario for $100 \%$ renewable energy share by the year 2050 .

\section{Global North and Global South: Two representing regions}

The region from the GN is the Dutch province of Overijssel located in the east of the Netherlands sharing its eastern border with Germany. The province covers a land area of $3,327 \mathrm{~km}^{2}$, with a population of 1.15 million as of the year 2019. The gender ratio in the region is approximately equal and the average population age is 40 years (Province of Overijssel, 2019). The province of Overijssel

\footnotetext{
${ }^{2}$ The full explanation of the methodology can be found in Jain, Schrutir, ENERGY TRANSITION IN GLOBAL NORTHSOUTH DIMENSION: CASE OF OVERIJSSEL AND MATHURA, Enschede 2020 (master thesis)
} 
has half of its population living in urban cities, while the other half is living in rural areas with agriculture and tourism as core economic activities.

The energy supply in the Overijssel is accounted to be 102.8 PJ for domestic, commercial and transportation in the year 2015 (Beursken, Reffeltrath, \& Menkveld, 2016). Among the energy delivered, only $9 \%$ of energy is generated from renewable energy sources that include wind, solar, geothermal, bioenergy and biofuels. The rest of the energy is generated by fossil fuels like coal and natural gas and imported from outside the region. See table 1. 


\begin{tabular}{|c|c|c|}
\hline Total Energy Demand in Overijssel (Year 2015) & \multicolumn{2}{|c|}{28.5 TWh } \\
\hline Household & \multicolumn{2}{|c|}{7.7 TWh } \\
\cline { 2 - 3 } & $1.6 \mathrm{TWh}$ (Electricity) & 5.2 TWh (Heating) \\
\hline Commercial/ Industries & \multicolumn{2}{|c|}{$11.1 \mathrm{TWh}$} \\
\cline { 2 - 3 } & $2.5 \mathrm{TWh}$ (Electricity) & 7.5 TWh (Heating) \\
\hline Transportation & \multicolumn{2}{|c|}{$9.4 \mathrm{TWh}$} \\
\hline Energy derived from Fossil fuels or imported & \multicolumn{2}{|c|}{$\mathbf{2 5 . 8} \mathbf{T W h}$} \\
\hline Total Renewable Energy Generated & \multicolumn{2}{|c|}{$\mathbf{2 . 6}$ TWh } \\
\hline
\end{tabular}

Table 1: Energy consumption and generation source in Overijssel

The second region, representing the GS is the Mathura district located in the northern part of India in the Uttar Pradesh state. The district covers an area of $3,329.4 \mathrm{~km}^{2}$, with a population of 2.54 million as recorded in the census in the year 2011. The region is famous for its religious heritage and attracts tourists throughout the year. The region is a combination of rural and urban cities connected with public transport. The gender ratio in the region is unbalanced towards males and has a literacy rate of approximately $72 \%$. The region has a strong base for agriculture and cattle farming. Approximately $75 \%$ of the land available in the region is utilized for agriculture and cattle farming (Appendix B).

The energy demand in the region is sufficed through importing electricity by thermal power plants from adjoining districts that provides electricity 24 hours a day with minor interruptions. While LPG for cooking and petroleum for transportation fuel is imported majorly from the middle east countries with minor generation from other parts of the country. Table 2 shows the approximate energy data.

\begin{tabular}{|c|c|}
\hline Estimated Energy Consumption in Mathura District & $\mathbf{4 . 3}$ TWh \\
\hline Electricity Consumption & 1.9 TWh \\
\hline LPG consumption & 0.7 TWh \\
\hline Biomass Consumption for Cooking & 0.38 TWh \\
\hline Transportation & 1.3 TWh \\
\hline Energy derived from Fossil fuels or imported & $\mathbf{4 . 3} \mathbf{T W h}$ \\
\hline Total Renewable Energy Generated & $\mathbf{0 ~ P J}$ \\
\hline
\end{tabular}

Table 2: Energy consumption and generation source in Mathura 
When we examine the equivalent carbon emission and the estimated techno-economic cost in table 3 for the energy systems of the two regions, we empirically observe a significant difference between Overijssel and Mathura.

\begin{tabular}{|c|c|c|}
\hline Reference Scenario & Overijssel & Mathura \\
\hline Eq. Carbon Emission (Mton) & 7.09 & 2.37 \\
\hline Techno-Economic Cost (in million $€$ ) & $€ 1540$ million & $€ 168$ million \\
\hline
\end{tabular}

Table 3: Distinction in Carbon Emission and Techno-Economic Cost for Reference Scenario between Overijssel and Mathura

Overijssel has higher emissions and cost as compared to Mathura due to the distinction in the energy profile that confirms the differences in energy context between GN and GS countries. As will be shown below, these differences continue in the future when both regions are transforming their current energy system into a renewable based sustainable one, despite the better position of Mathura with respect to availability of renewable resources. From table 4, we can see the differences in the amount of annual energy potential of resources between the two regions.

\begin{tabular}{|c|c|c|}
\hline \multirow{2}{*}{ Renewable Energy Resource } & \multicolumn{2}{|c|}{ Annual Energy Potential } \\
\cline { 2 - 3 } & Overijssel & Mathura \\
\hline Bioenergy Potential & $12.64 \mathrm{TWh}$ & $27.15 \mathrm{TWh}$ \\
\hline Pruning $W o o d$ & $6.6 \mathrm{TWh}$ & $0.47 \mathrm{TWh}$ \\
\hline Organic Feedstock & $1.83 \mathrm{TWh}$ & $6 \mathrm{TWh}$ \\
\hline Agriculture $W$ aste & $0.35 \mathrm{TWh}$ & $>16.5 \mathrm{TWh}$ \\
\hline$M S W$ & $3.86 \mathrm{TWh}$ & $4.18 \mathrm{TWh}$ \\
\hline Solar Energy Potential (Panel $\eta=18 \%)$ & $182 \mathrm{kWh} / \mathrm{m}^{2}$ & $354.19 \mathrm{kWh} / \mathrm{m}^{2}$ \\
\hline Wind Energy Density & $240 \mathrm{kWh} / \mathrm{m}^{2}$ & $200 \mathrm{kWh} / \mathrm{m}^{2}$ \\
\hline Geothermal Energy Potential & $0.72 \mathrm{TWh}$ & - \\
\hline River Hydro Energy Potential & - & $0.26 \mathrm{TWh}$ \\
\hline
\end{tabular}

Table 4: Available renewable energy resources in Overijssel and Mathura (Appendix B)

As we can see from table 4, except for wind, Mathura's position in all other renewable resources is far better than the position of Overijssel. In particular biomass and the sun provide high renewable potential in Mathura if the region is able to exploit the renewable resources. Moreover, here the difference in economic position and energy context will be a hindering factor to benefit energetically from the rich renewable resource potential in the GS region. The next section will show this point by two scenario analysis we did for both regions. One scenario showing the Business as Usual (BAU) and one scenario assuming a complete renewable based energy system in 2050. 


\section{Energy Transition Scenarios in Overijssel (GN) and Mathura (GS)}

This section analyses and compares the regional sustainable energy transition potential in Overijssel and Mathura in two scenarios. The first scenario is the BAU scenario, which represents the autonomous energy developments in both regions. Renewables resources can but need not be part of this autonomous development. Given the current domination of fossil resources in both regions, it is not unrealistic to assume a continued application of these resources in the coming decades. Our second scenario is a $100 \%$ renewable based energy system in 2050, without any direct carbon emissions.

\section{Business-as-Usual Scenario}

The possible development in energy consumption for the GN region Overijssel and the GS region Mathura for the year 2050 under the BAU scenario can be seen in the Table 5 .

\begin{tabular}{|c|c|c|}
\hline \multirow{2}{*}{ ENERGY DEMAND } & \multicolumn{2}{|c|}{ BAU } \\
\cline { 2 - 3 } & Overijssel & Mathura \\
\hline Electricity Demand $($ in $T W h)$ & 4.02 & 7.17 \\
\hline Cooking Fuel Demand $($ in $T W h)$ & - & 1.6 \\
\hline Heating Demand $($ in $T W h)$ & 5.21 & - \\
\hline Industrial Fuel $($ in $T W h)$ & 7 & - \\
\hline Transportation Fuel Demand $($ in $T W h)$ & 10.5 & 8 \\
\hline Total Billion km/yr & 20 & 12 \\
\hline Total Energy Demand (in TWh) & $\mathbf{2 6 . 7 3}$ & $\mathbf{1 6 . 7 7}$ \\
\hline
\end{tabular}

Table 5: Comparison between the expected energy demand in Overijssel and Mathura in BAU scenario

A study from KIVI Engineering society understands that the energy consumption for Netherlands will show marginal deviation in the year 2050, if similar trends of energy system transition is followed. The possible rise in consumption per person to maintain quality of life that is neutralized by determination to improve their energy efficiency. Based on this study, we made a similar assessment for Overijssel owing to historical trends ${ }^{3}$. On the other hand, Mathura will witness a spike in its energy consumption due to growing population and GDP growth influencing the quality of life and therefore energy demand according to World Energy Annual Report 2018-2050.

To satiate these energy demands, the BAU scenario is simulated (Appendix C) and table 6, shows the resource utilization to generate energy in both the regions,

\footnotetext{
${ }^{3}$ See reference in footnote 2 above.
} 


\begin{tabular}{|c|c|c|}
\hline \multirow{2}{*}{ Resources } & \multicolumn{2}{|c|}{ BAU } \\
\cline { 2 - 3 } & Overijssel & Mathura \\
\hline Coal & 3.7 & 18.14 \\
\hline Natural Gas & 18.67 & 2.57 \\
\hline Petroleum Fuel & 5.9 & 5.6 \\
\hline Solar Energy & 0.23 & 0.28 \\
\hline Wind Energy & 0.18 & 0 \\
\hline Geothermal Energy & 0.13 & 0 \\
\hline Bioresources & 4.9 & 2.2 \\
\hline
\end{tabular}

Table 6: Resources utilized for energy generation in Overijssel and Matbura in BAU scenario

Overijssel should be expected to have approximately $15 \%$ of the renewable energy share in the BAU scenario considering the current pace of energy development and planning by the provincial government. Natural gas will remain the dominant energy resource for the province. On the other hand, Mathura will only be able to add $8.5 \%$ of renewable energy share to their total primary energy supply. Coal will be the dominant resource for energy generation, while the renewable energy share will majorly consist of wet biomass from animal feedstock and high solar irradiation.

Based on the resources utilized and the system implemented, we observe the equivalent carbon emission and annual techno-economic cost as results of the autonomous development of energy system between both the globalized regions in table 7 .

\begin{tabular}{|c|c|c|}
\hline Business-s-Usual (Year 2050) & Overijssel & Mathura \\
\hline Eq. Carbon Emission (Mton) & 6.27 & 8.43 \\
\hline Total Annual Cost (In million $€$ ) & $€ 2257$ & $€ 1381$ \\
\hline
\end{tabular}

Table 7: Distinction in equivalent Carbon Emission and Techno-Economic Cost for BAU Scenario between Overijssel and Mathura

The GS region Mathura will have a higher carbon emission than Overijssel as their energy consumption increases. Although, the energy consumption in Overijssel is still higher than Mathura, but energy efficiency measures lowers the carbon emission in Overijssel as compared to the reference scenario. Additionally, the techno-economic cost of Overijssel for the BAU scenario will also remain to be higher than Mathura. 


\section{Energy Transition Scenario for 2050}

The energy transition scenario for the year 2050 aims to attain energy neutrality for Overijssel and Mathura. The scenario is formulated based on the projected energy demand based on the proposed emission reduction and energy efficiency targets and expected economic and societal growth for the particular region that can be seen in table 8 .

\begin{tabular}{|c|c|c|}
\hline \multirow{2}{*}{ ENERGY DEMAND } & \multicolumn{2}{|c|}{ BAU } \\
\cline { 2 - 3 } & Overijssel & Mathura \\
\hline Electricity Demand $($ in $T W h)$ & 2.27 & 7.32 \\
\hline Cooking Fuel Demand $(i n T W h)$ & - & 1.6 \\
\hline Heating Demand $(i n T W h)$ & 2.64 & - \\
\hline Industrial Fuel (in $T W h)$ & 4.6 & 3.12 \\
\hline Transportation Fuel Demand (in $T W h)$ & 4.04 & 12 \\
\hline Total Billion km/yr & 20 & $\mathbf{1 2 . 0 4}$ \\
\hline Total Energy Demand (in $T W h$ ) & $\mathbf{1 3 . 5 5}$ & \\
\hline
\end{tabular}

Table 8: Projected energy demand for Overijssel and Mathura in the Energy Transition Scenario $2050^{4}$.

The study by KIVI engineering society also understands that, if the Netherlands can achieve their emission, energy efficiency and renewable energy targets, their energy consumption can reduce by 50\% by the year 2050 (Persoon, Luitjens, Boonstra, \& Moerkerken., 2017) and consequently a similar trend can be assumed for Overijssel. On the other hand, World Annual energy report 2017 predicts higher energy consumption for India and consequently Mathura due to economic growth and rising population index (Li, 2018).

The energy system is modelled considering the resource potential of the two regions and the results of the simulations (Appendix C) can be seen in Table 9.

\footnotetext{
${ }^{4}$ See reference in footnote 2 above.
} 


\begin{tabular}{|c|c|c|}
\hline Energy Transition 2050 & Overijssel & Mathura \\
\hline Energy Generation Resources (in TWh) & & \\
\hline Solar Energy & 2.86 & 3.41 \\
\hline Wind Energy & 0.84 & 0.40 \\
\hline Run-Off River Hydro & - & 0.26 \\
\hline Geothermal Energy & 0.88 & - \\
\hline Bioresources & 16.63 & 22.63 \\
\hline Electric Battery Technology (in GWh) & 9 & 12 \\
\hline Heating Storage & 5 & - \\
\hline Carbon Emission (Mton) & $\mathbf{0}$ & $\mathbf{0}$ \\
\hline Annual Techno-Economic Cost (in million $\mathbf{~ ) ~}$ & $\mathbf{€ ~ 8 8 7}$ & $\mathbf{€ 1 2 0 7}$ \\
\hline
\end{tabular}

Table 9: Distinction between Energy Generation Resources, Carbon Emission and Techno-economic Cost for the Energy Transition 2050 scenario between Overijssel and Mathura

The energy neutral scenario results in a carbon neutral energy system for both the regions. However, when we observe the techno-economic cost, Mathura presents a high cost as compared to Overijssel. The energy system in both regions is dominated by bioresources due to their economic activities. The green gas produced in Overijssel can be used as an alternative of natural gas for thermal comfort, while for Mathura it would suffice the need for cooking fuel.

Furthermore, access to bioresources are limited to suffice the complete energy demand in both regions. Therefore, diverse energy systems utilizing different resources available in the region have to be added in the energy planning. Moreover, both the regions intend to make a transition to electric vehicles (Chao, 2017) (Mission Zero, 2019) to integrate larger share of renewables and improving the energy efficiency. Though the transportation sector will marginally be supported by biofuels and green gas.

For Overijssel, sun, geothermal and wind resources are to be used to provide additional energy. The energy efficiency will be improved by formulating a synergy between consumption and generation sections by expected technological development. This would in turn reduce the energy consumption leading to reduction in economic cost and emissions. The alternative energy system other than bioresources can be further increased, but they might face limitation with grid stability. Therefore, further research and technological advancement are required in energy generation and storage to supplement the shortfall as the bioresources in Overijssel might not be sufficiently available for this energy neutral scenario. 
For Mathura, with ample irradiation, the energy system will be supported by solar energy system and meagrely by wind energy and run-off river hydro system. The utilization of biomass is a priority as it would reduce the carbon emission that usually occurs from burning crop residue or dumping into landfills. Conversely, solar panels encounter barriers on the roof due to dense construction (DTE Staff, 2019), therefore commercial solar PV farm is required on fallow land and river coast, thus, not having an impact on the land footprint.

\section{Implications of Sustainable Energy Transition}

The realization for energy transition and attaining energy neutrality in both the Overijssel and Mathura are dependent on the regional approach considering regulations, economic strength, and social factors. Both the regions are dominated with agricultural and cattle farming activities making bioresources available for energy generation. Additionally, both regions are also influenced by strong tourism industry that demotivates the installation of inland wind turbines in the region. While the installation of solar panels is motivating in both regions and highly beneficial in Mathura due to warm weather conditions and ample sunlight.

However, on examining the implications socially, the energy system in Overijssel must make a transition by maintaining energy security and affordability of energy. It must be combined with a transition to energy-efficient industrial processes and homes in the region. However, social acceptance and regulations have a vital role in implementation of renewable energy technologies in the Dutch region. The challenges like NIMBY (not in my backyard) are experienced by the citizens and there are stringent political regulations in utilization of bioresources citing sustainability issues.

Contrarily, the energy transition in Mathura, is amiable to eliminate the shortage of power and growing health issues due to using of unsustainable energy resources. Therefore, the implementation of energy system is socially acceptable and the regulations from the government are cordial. Thus, the transition must be strategically planned by satiating the growing need for energy along with a transformation of the current energy system in place, providing a secure and reliable supply of energy as it was absent in the previous years.

There is proactive planning for transition in the GN and Overijssel as the province has pre-determined criterion for spatial zoning to installing renewable energy in the region (Hoppe, Dijk, \& Arentsen, 2011). It involves diverse stakeholders and applies the democratic and social awareness approach. The GS region Mathura do not have a strategic plan for transition. The regions just participate in the 
national targets and do not emphasis on regional transition in the energy system. Any transformation in the region will be supported by a top down approach.

Furthermore, Mathura being in India is a part of booming economy yet is economically weaker in comparison to Overijssel. Therefore, considering the techno-economic cost in the energy transition scenario 2050, the energy transition in Mathura could be hindered economically. The GS region will not be able to invest much in research to accelerate the process of energy transition and continue to implement the existing technologies. Contrarily, Overijssel being part of the GN Netherlands is economically stronger that allows them to invest in research and technology innovation. Such investment results in advanced and affordable technologies that can accelerate the process of energy transition.

An example on the financial implication on energy system can be viewed in terms of transition in transportation sector. Based on the national targets, both regions aim to make a transportation transition from fossil fuels to electrical vehicles by the year 2030 (Chao, 2017) (Mission Zero, 2019). The integration of electric vehicle in Overijssel has been initiated with the introduction of public vehicle charging stations. However, the plan of electric mobility in India and Mathura is only at a primary stage.

\section{Conclusion}

The starting point of the paper was a lack of knowledge of how country scenarios on renewable energy transition translate to the regions where the energy transition is supposed to be implemented. Knowing the differences between the energy transition potential in GN and GS countries, we raised the question how these differences would manifest in the regions in countries belonging to the GN and the GS. Our guiding question was: What are the differences and similarities in the regional sustainable energy transition in the Global North and Global South, with the region Overijssel in the Netherlands and the region Matura in India as illustrative examples?

We started answering this question by analysing the differences between the Global North and Global South country blocks in the world. These blocks represent a clear demarcation in several global debates, among others on climate change and energy transition. The differences in particular manifest in economic and financial potential to modernise and sustain energy systems. However, a closer look at two representing regions, Overijssel for the GN and Matura for the GS also showed similarities in socio-economic outlook and renewable energy resource potential. Both regions have agriculture, cattle 
farming and tourism as major economic activities one a comparable geographical area with high bioresources potential. On the short term the differences between both regions showed to be substantial due socio-economic and demographic differences. These differences also showed in the comparison of the current energy system in both regions. However, looking ahead to 2050, the differences become smaller, in particular with respect to energy consumption and accompanying emissions and costs as analysed and compared in the BAU scenario. In Overijssel the energy consumption hardly changes due to continued efficiency improvements whereas the energy consumption in Matura increases due to increasing population and economic development. However, the energy portfolio in Overijssel also does not change significantly in the BAU scenario reducing the CO2 gap between Overijssel and Matura. The costs of the BAU scenario are significantly higher in Overijssel compared to Matura.

The comparison of the zero emission scenarios for 2050 continues the trend in the BAU scenario: the movement in both regions towards each other in a zero emission energy system development. In both regions bioresources are the dominant renewable resource in an locally determined energy resource portfolio. However, the costs of getting into this longer term position are significantly higher in Matura than in Overijssel, whereas the general economic potential, as it looks in 2020, is worse in Matura. Our analysis therefore indicates that a renewable energy transition in the longer term can result in zero emission systems in both GN and GS countries, but with substantial differences in costs. 


\section{Appendix A: EnergyPLAN Software and Input Data}

EnergyPLAN software presents a medium to the research community to validate their energy transition scenarios. It has been used in researches to design and simulate national and regional energy planning strategies by formulating a synergy among energy systems (EnergyPLAN, 2017). Furthermore, the scenario timeframe required is one year with a one-hour time step and has the luxury to be combined and create a scenario for multiple years (Connolly, Lund, Mathiesen, \& Leahy, 2010).

The acquisition of input data required to run the simulations in the energyPLAN model for the study and is described in this section

Energy and

Technology Cost Data

\section{Distribution Profile}

Reorganization of data

to input into the

EnergyPLAN tool
Entering the Data into

EnergyPLAN

Figure 4.1: Process Flow for Data to be utilized in energy PLAN

\section{Energy Data}

The static data of the energy for the province of Overijssel is collected from the official website http://www.overijssel.nl and the previous year data for energy is collected from https://klimaatmonitor.databank.nl. The data collected includes energy consumption through electricity, heating and transportation across all sectors.

On the other hand, for the district of Mathura, the electricity data was collected by contacting the local authorities and was provided by Dakshinanchal Vidyut Vitran Nigam Limited (DNVVNL). The transportation consumption data is not available with the local authorities. Therefore, an assumption is based on contact with local authority and owner of a fuel station and presumed to be the same for all registered fuel station in the district. While the cooking fuel data is acquired from the official Assessment report on LPG cooking fuel by CRISIL: An S\&P Global Company in June 2016.

The predictive energy data for the year 2030-2050 is not available for Overijssel and Mathura. However, there are different studies elaborating diverse energy scenario and expected energy consumption of the Netherlands and Mathura. Based on the historical trends for Overijssel and the 
Netherlands, the energy consumption data for the years 2030-2050 is assumed with higher integration of renewable energy share and energy efficiency.

On the other hand, historical trend for Mathura and India is unavailable therefore, an expected energy consumption for the district is assumed with the trend of the reference scenario. Meanwhile, the energy consumption for business-as-usual and energy transition scenario is the same for Mathura with a view of development of 100\% electrification along with growth in population, economy, and standard of living.

\section{Obtaining Distribution Profile}

The distribution profile is required to know the hourly energy demand and weather conditions to determine the energy supply from the renewable energy system. The energy consumption profile for electricity and gas for Overijssel is acquired from Liander. The downloaded distribution profile is a generic one from the year 2008 and assumed for the province. Additionally, the tool requires solar and wind data to evaluate the actual energy production from solar energy and wind energy systems. The hourly weather profile of Overijssel is downloaded from Meteorological Data Portal for TU Delft (https://www.tudelft.nl/). The dataset consisted of one year constructed from weather data averaged over a multitude of years, with a one-hour time resolution.

Table A1: Distribution Profiles and Data Sources for Overijssel

\begin{tabular}{|c|c|c|}
\hline Distribution & Timespan & Source \\
\hline Solar irradiance & Average 1991- 2018 & TU Delft \\
\hline Wind speed & Average 1991- 2018 & TU Delft \\
\hline Electricity demand & 2008 & Liander \\
\hline Gas/heat demand & 2008 & Liander \\
\hline Transport BEV & Basic Data Profile & EnergyPLAN \\
\hline Constant & Value 1 for all hours & EnergyPLAN \\
\hline
\end{tabular}

The distribution profile for the Mathura region is not available due to administrative regulations. Therefore, the profile is formulated by using the Artificial Load Profile Generator (ALPG). ALPG is an open-source software developed by the University of Twente and simulates load profile for electricity and heating with constraints from controllable domestic devices. However, for Mathura, these controllable domestic devices are not used, and a basic electricity profile is developed based on the demographics of the city. The weather profile for the district is downloaded from Solar Radiation Data (SoDa) website (http://www.soda-pro.com/) and are at a one-hour time step. 
Table A1: Distribution Profiles and Data Sources for Mathura

\begin{tabular}{|c|c|c|}
\hline Distribution & Timespan & Source \\
\hline Solar irradiance & 2018 & SoDa \\
\hline Wind speed & 2018 & SoDa \\
\hline Electricity demand & Monthly Average 2018 & DNNVL \\
\hline Gas/heat demand & Not Applicable & Not Applicable \\
\hline Transport BEV & Basic Data Profile & EnergyPLAN \\
\hline Constant & Value 1 for all hours & EnergyPLAN \\
\hline
\end{tabular}

\section{Influence of data on Simulations}

The results of the simulation are dependent on the data set and the distribution profile uploaded into the software. The energy distribution profile for Overijssel is from 2008, while the static data is current. An alteration in the results is expected if the current data set is used and applied for future scenarios. These alterations are due to changes in the behavior of consumers and the introduction of new and efficient appliances. Similarly, the data set for Mathura was not available with ease and needed to be extrapolated from one month, while the distribution profile is generated through ALPG. The software generates a comparable profile for the Netherlands. However, the societal differences between India and the Netherlands will generate a comparable difference in the manner of distribution.

Lastly, the simulations are influenced by the regulations criteria to reduce CEEP (Critical Excess Electricity Production) and to maintain the grid stabilization. The CEEP strategy for both the regions is selected separately, while the grid stabilization share has been the same for both the regions to 0.3. 


\section{Appendix B: Energy Resource Potential}

This section estimates the energy resource potential for Overijssel and Mathura.

\section{Bioresource Energy Potential}

The energy from bioresources are evaluated and extracted from pruning wood, municipal solid waste, organic feedstock, and agriculture waste.

\section{Pruning Wood Calculation}

To simplify the calculation for availability of pruning wood, we take an assumption that both regions have oak tree (Tree species that are common in the Dutch woods., n.d.). Further, to have an estimation on total number of trees in one hectare of land, we use an online tree calculator with an average distance between each oak tree to be 10 feet (Tree Spacing Calculator, 2000).

The weight of an oak tree with 16 inches of DBH and 60 feet height is around 1 ton (David W. Patterson). A young tree can be pruned $25 \%$ and middle-aged tree can be pruned $20 \%$ while an old and mature tree can be pruned $10-15 \%$. The pruning of wood is based on the photosynthesizing foliage to remain healthy and the tree can withstand the pruning. (Purcell, 2015)

Over here, we take the pruning of the wood to be $5 \%$ as both the region, which will vary in their pruning percentage and the weight of the wood. Therefore, the wood pruned from one tree is $5 \%$ of 1 ton $=0.05$ ton with an average lower heating value of wood is $4.00 \mathrm{kWh} / \mathrm{kg}$ (Bisaglia, et al., 2018) Therefore, for 1 hectare of forest land, the total weight of pruned wood will be,

0.05 ton $/$ tree $\times 1100$ trees $/$ ha $=55$ ton of pruning $\mathrm{wood} / \mathrm{ha}$

\section{Overijssel}

According to David Mohren (Vodde, 2006), Netherlands has around 360,000 ha of forest area, which is about of $10 \%$ of the total land area in Netherlands. It further mentions that the Eastern side of Netherlands has a forest cover ranging from $10 \%$ to $20 \%$. Since the pruning waste wood must be collected from the local regions of Overijssel. We assume that Overijssel has a forest cover of at least $10 \%$ of its total land area.

Land area of Overijssel Province $=332700$ ha

Forest cover $(10 \%$ of land area $)=33270$ ha

Therefore, the estimated energy present in Overijssel from pruning wood 
Pruning wood / ha * Lower heating Value * Tree land cover $=6.6 \mathrm{TWh}$

\section{$\underline{\text { Mathura }}$}

Similarly, for Mathura the forest land is estimated as 1592 ha and land under miscellaneous tree crops is 929 ha, therefore, the energy from pruning wood in Mathura region will be,

Pruning wood / ha * Lower heating Value * Tree land cover $=0.478 \mathrm{TWh}$

\section{Municipal Solid Waste}

The estimated energy content in MSW is $15 \mathrm{MJ} / \mathrm{kg}$ (Akkaya \& Demir, 2009) with an average MSW of $2.2 \mathrm{~kg} /$ capita/day for European countries and 1.1 for South Asian Countries(Hoornweg \& BhadaTata, 2012).

The province of Overijssel belonging to the European continent has a population of 1.15 million people in January 2019. Therefore, the energy potential available within the region every year from municipal solid waste is $\mathbf{3 . 8 6} \mathbf{T W h}$ annually.

Similarly, for Mathura, belonging to the South Asian region, has a population of 2.5 million people in year 2011. Therefore, the energy content from MSW will be 4.18 TWh

Energy Potential from MSW = Energy Content MJ/kg)*Average MSW (kg/capita/day) *Population* 365

\section{Agriculture Waste}

The total available land for agriculture in Overijssel is 202,620 ha. The average crop yield and the residue data is not available on the internet. Therefore, an alternative approach was used by determining the average agriculture residue in Europe i.e. 74.89 MT/year (Iqbal, et al., 2016) with an agriculture land area of 179 million ha (Land cover and land use, 2018). From this it is determined that $418 \mathrm{~kg}$ of agriculture waste is generated per ha per year and has an energy content of approximately 15 $\mathrm{MJ} / \mathrm{kg}$ (Gravalos, et al., 2016) . The estimate energy content is $0.35 \mathrm{TWh}$.

Energy Content in Agriculture Waste $=$ Agriculture Land Area Overijssel(ha) * Energy Content $(M J / k g))$

$$
\text { * Average agriculture residue }(\mathrm{kg} / \mathrm{ha})
$$

A similar pattern is utilized for Mathura, although, the estimation shows a large amount of agricultural waste available as the $75 \%$ of the land area is cultivated for farming. (https:/ / wmw.nabard.org/xls/uttardist/ mathura\%20-Dist profile.xls) 


\section{Organic Feedstock}

The organic feedstock for Overijssel is evaluated to be 6.6PJ (Hoppe, Dijk, \& Arentsen, 2011). While for Mathura it is calculated by the cattle population (bttps://mmw.nabard.org/xls/uttardist/mathura\%20Dist profile.xls) for wet biomass. It is assumed that $1 \mathrm{cow}$ or buffalo produces $10 \mathrm{~kg}$ of wet biomass daily (Biogas, 2019), which can produce $0.062 \mathrm{~m}^{3}$ of biogas (Kuria \& Maringa, 2008). Provided that the Mathura district holds a population of 867,630 cattle (cows and buffalos) which can be used to generate biogas with $65 \%$ methane content. Therefore, the region has a green gas potential of $1.43 \mathrm{TWh}$ annually.

\section{Energy Content from Organic Feedstock = Cattle Population * Manure Annually * $0.062 \mathrm{~m}^{3} / \mathrm{kg}$ * Upgradation \% * Energy Content of green gas $\left(\mathrm{MJ} / \mathrm{m}^{3}\right)$}

\section{Solar Energy Potential}

The energy potential from solar irradiation in Overijssel and Mathura is estimated by evaluating the hourly solar irradiation at one square meter for a solar panel with an assumed efficiency of $18 \%$.

Annual Energy Potential with a PV Panel $\left(\mathrm{kWh} / \mathrm{m}^{2}\right)=\sum\left[18 \%\right.$ * Solar Irradiation $\left.\left(W / \mathrm{m}^{2}\right)\right] / 1000$

\section{Wind Energy Potential}

The wind energy potential in Overijssel and Mathura is estimated by evaluating the hourly wind speed at $10 \mathrm{~m}$ height recorded by TU Delft for Overijssel and SoDa for Mathura at one square meter of the turbine.

Annual Wind Energy Potential $\left(\mathrm{kWh} / \mathrm{m}^{2}\right)=\sum\left[0.5 *\right.$ Hourly Air Density * (Wind Speed) $\left.{ }^{\wedge} 3(\mathrm{~m} / \mathrm{s})\right]$

\section{Geothermal Potential}

Geothermal energy for thermal comfort and electricity is another source of energy explored in the region. In 2015, the region was supplying $0.13 \mathrm{TWh}$ of energy with an expected increase to $0.48 \mathrm{TWh}$ in 2030 (Beursken, Reffeltrath, \& Menkveld, 2016). With possible innovation and efficiency improvement, the geothermal energy potential is assumed to be $0.72 \mathrm{TWh}$

\section{River run-off Hydro Energy Potential}

River Yamuna passes through the district of Mathura and is among the largest rivers in the country in terms of length and flow rate. The river records an average flow rate of 2,950 $\mathrm{m}^{3} / \mathrm{s}$. The planning for river interconnection in India along with the high flow rate of the river can be utilized to install small 
sized run-off river hydropower plant, which can be used to provide base power to the region and an irrigation network for farms. 


\section{Appendix C: Simulation Results}

\section{C.1. Overijssel BAU Scenario Results}

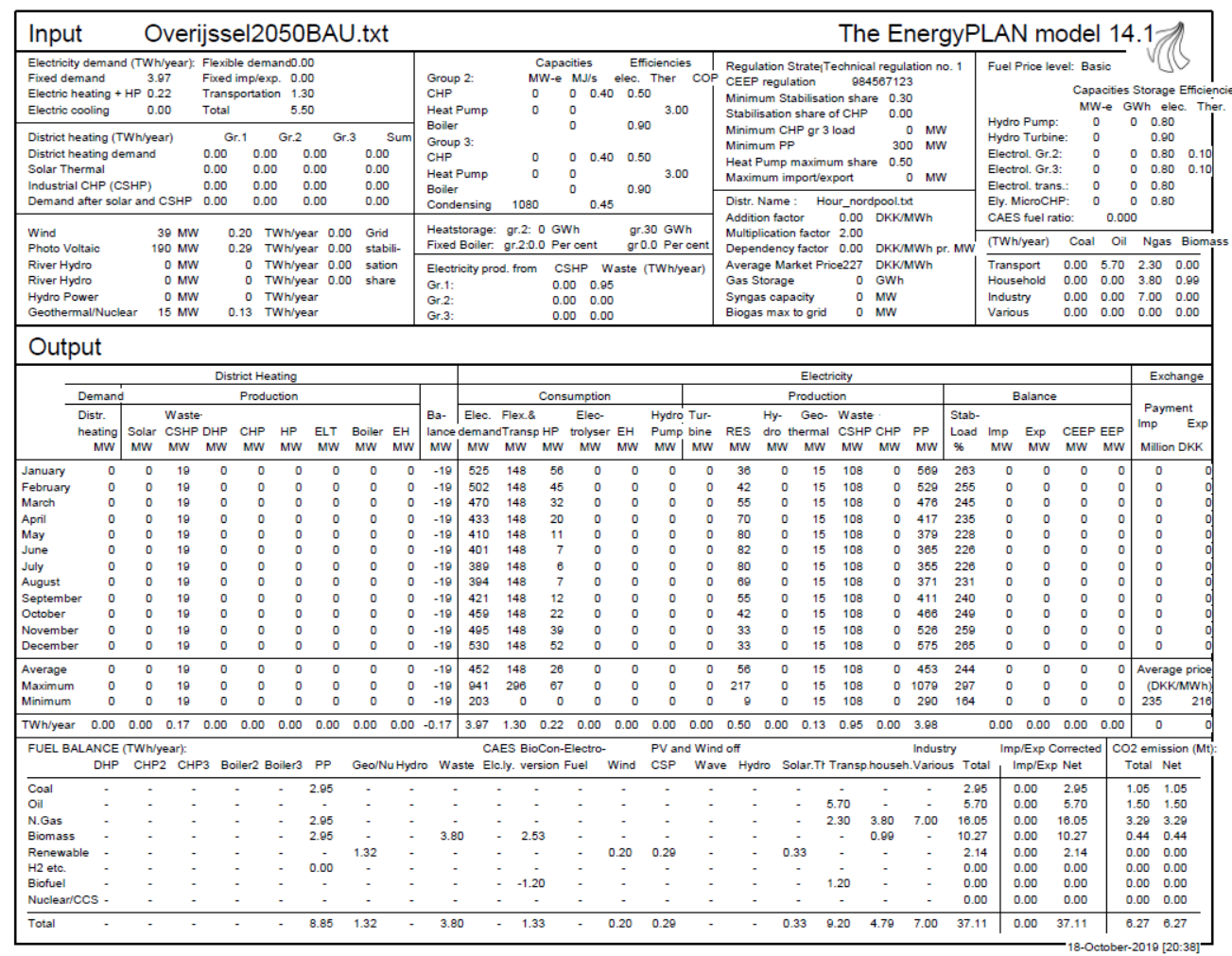

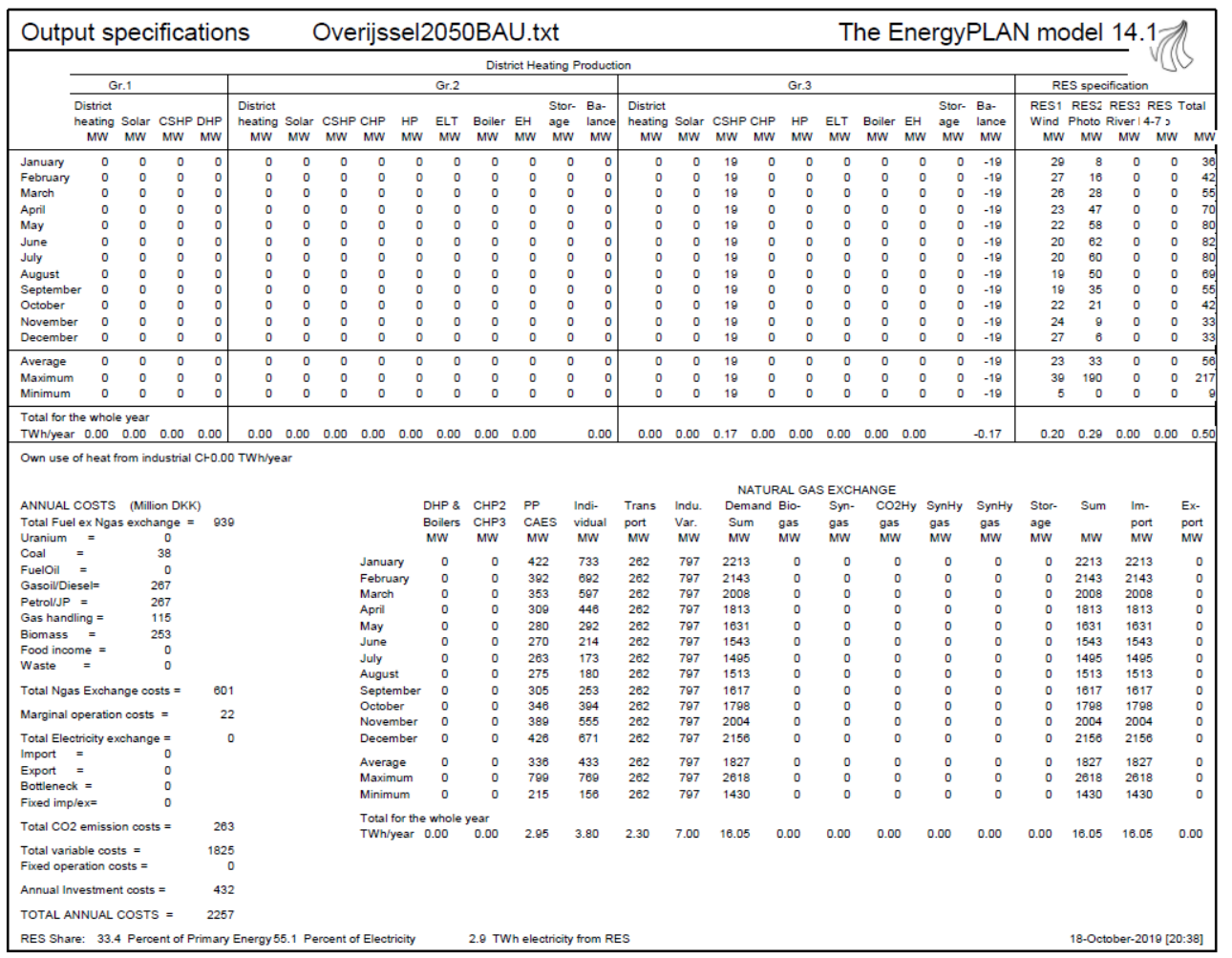




\section{C.2. Overijssel Energy Transition 2050}

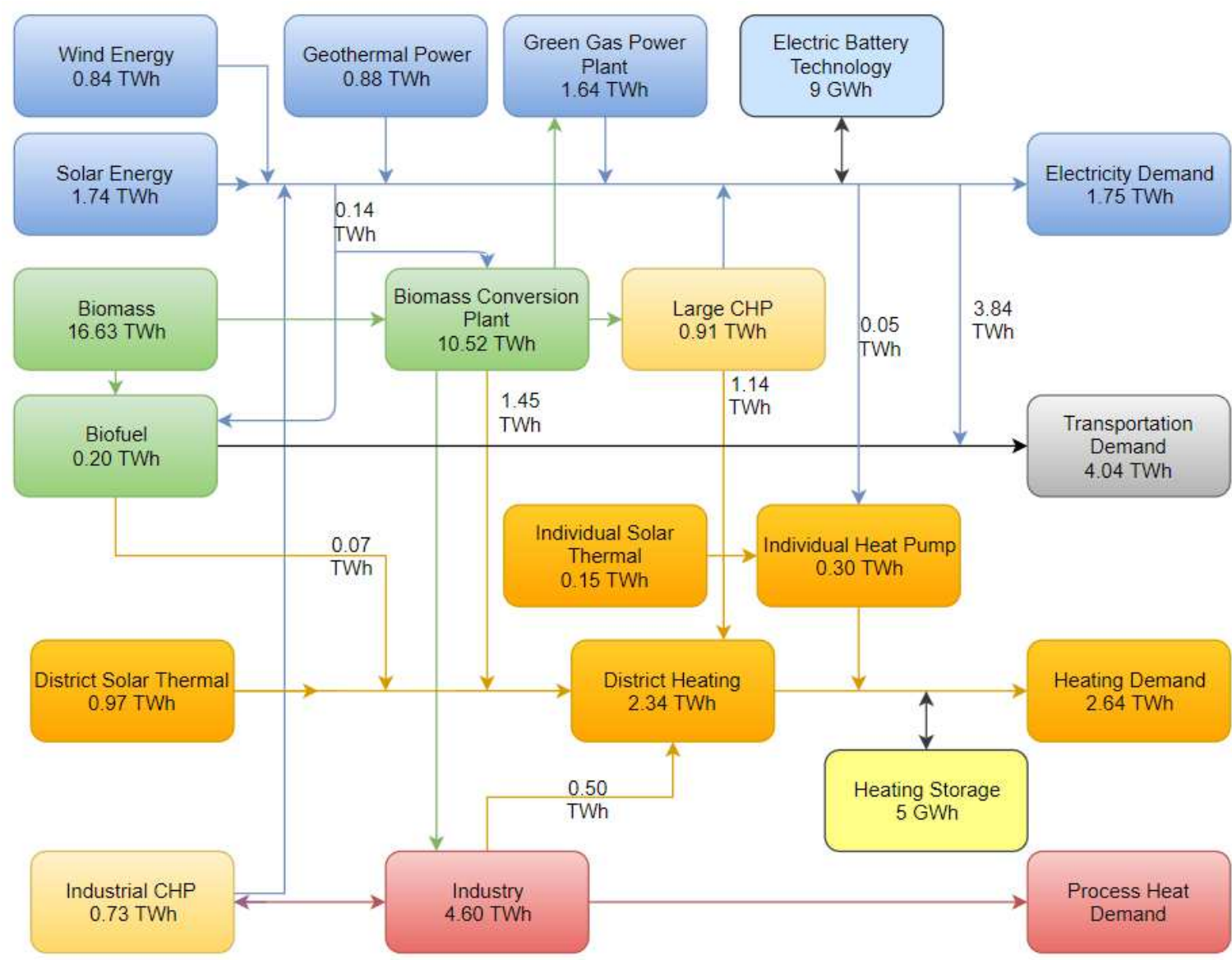

Figure 3: Energy Flow Chart for Overijssel Energy Transition Scenario 2050 


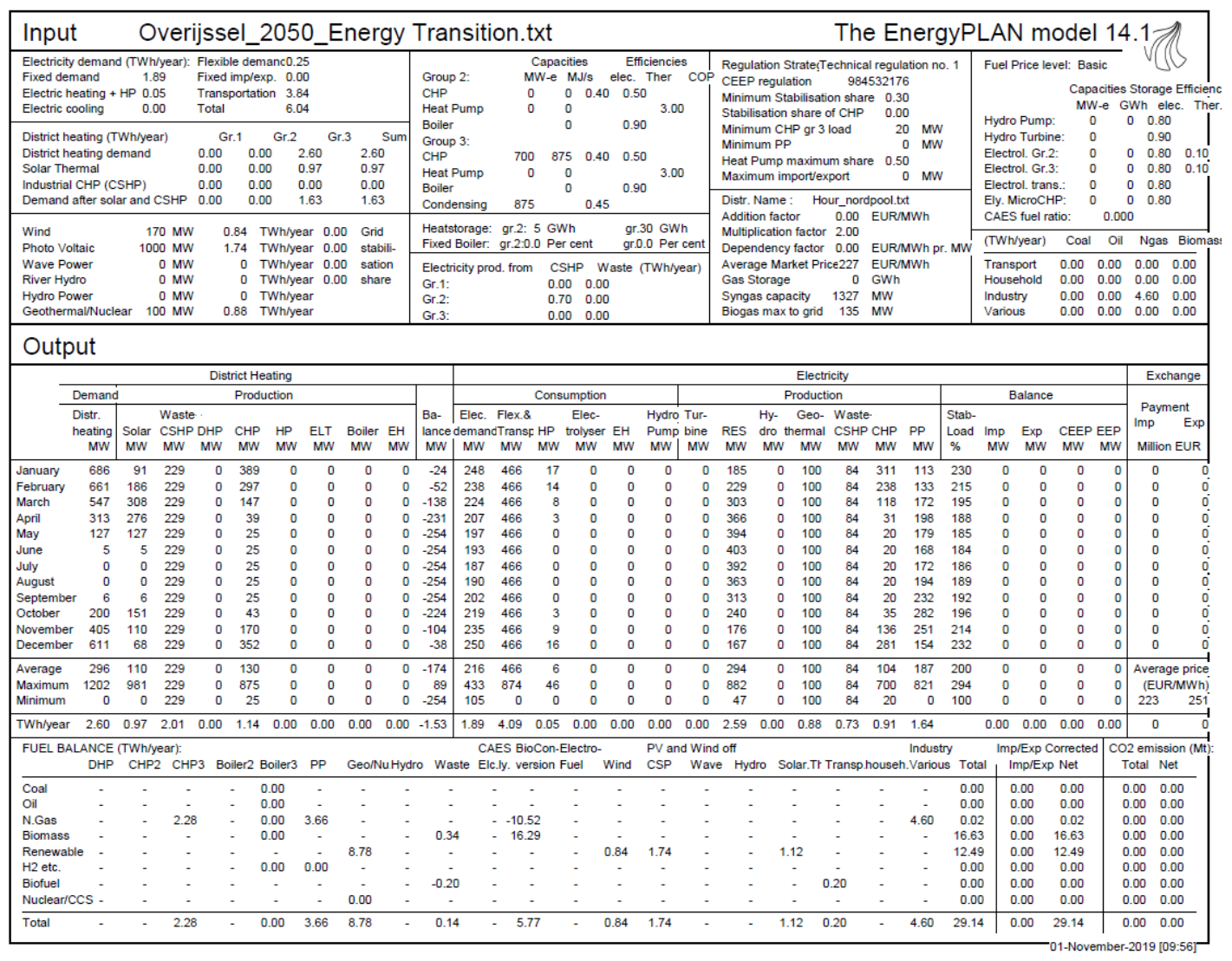

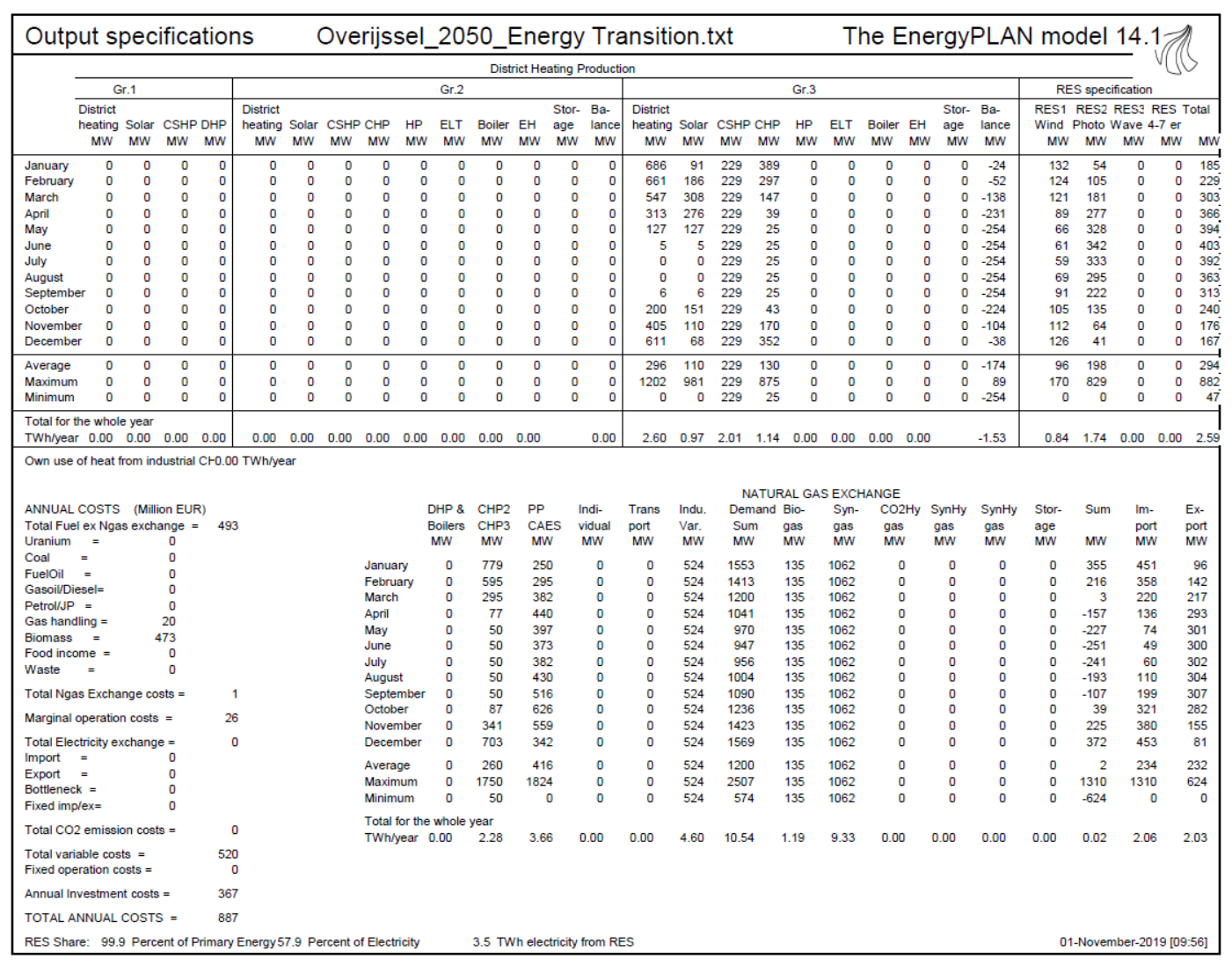




\section{C.3. Mathura BAU Scenario Results}

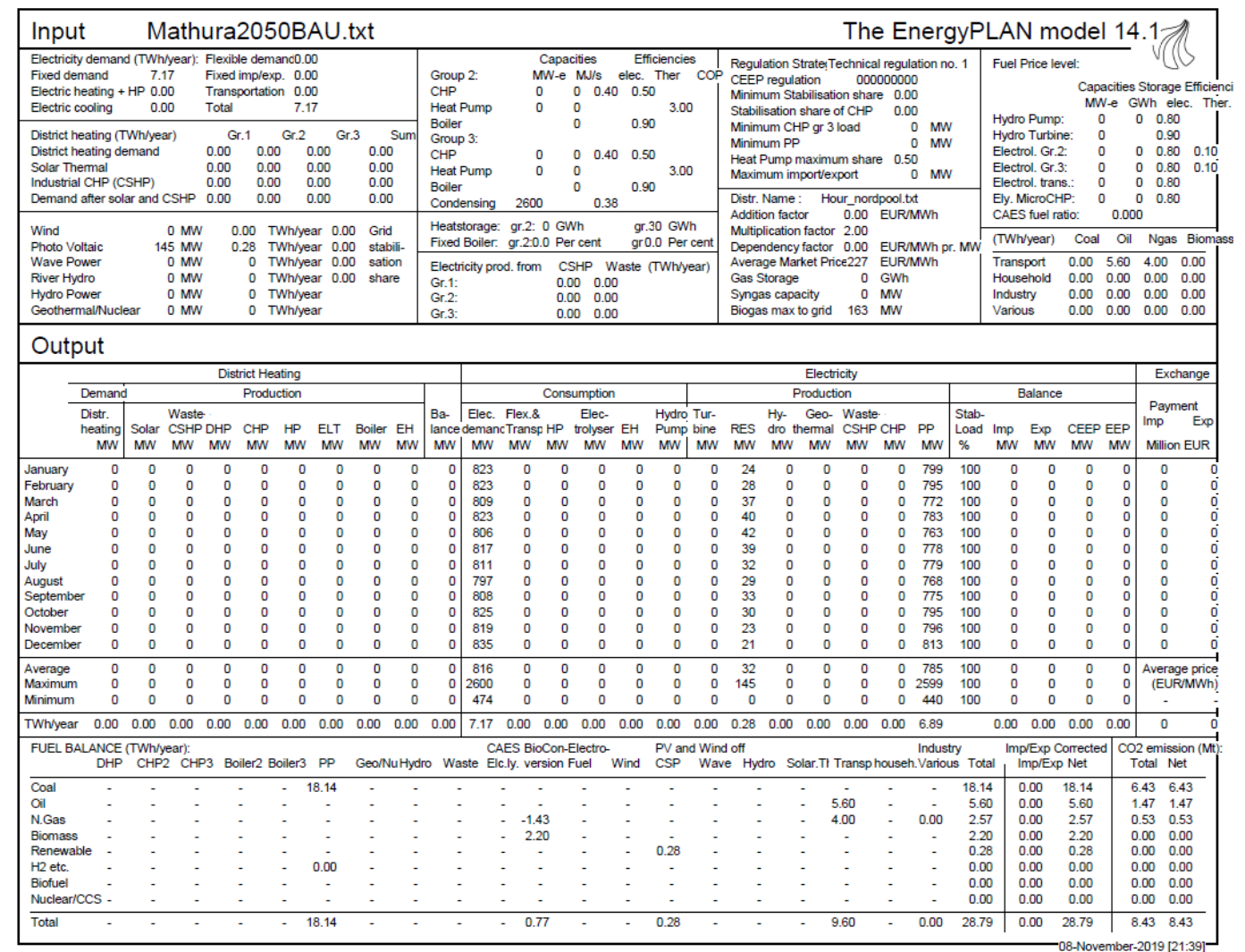

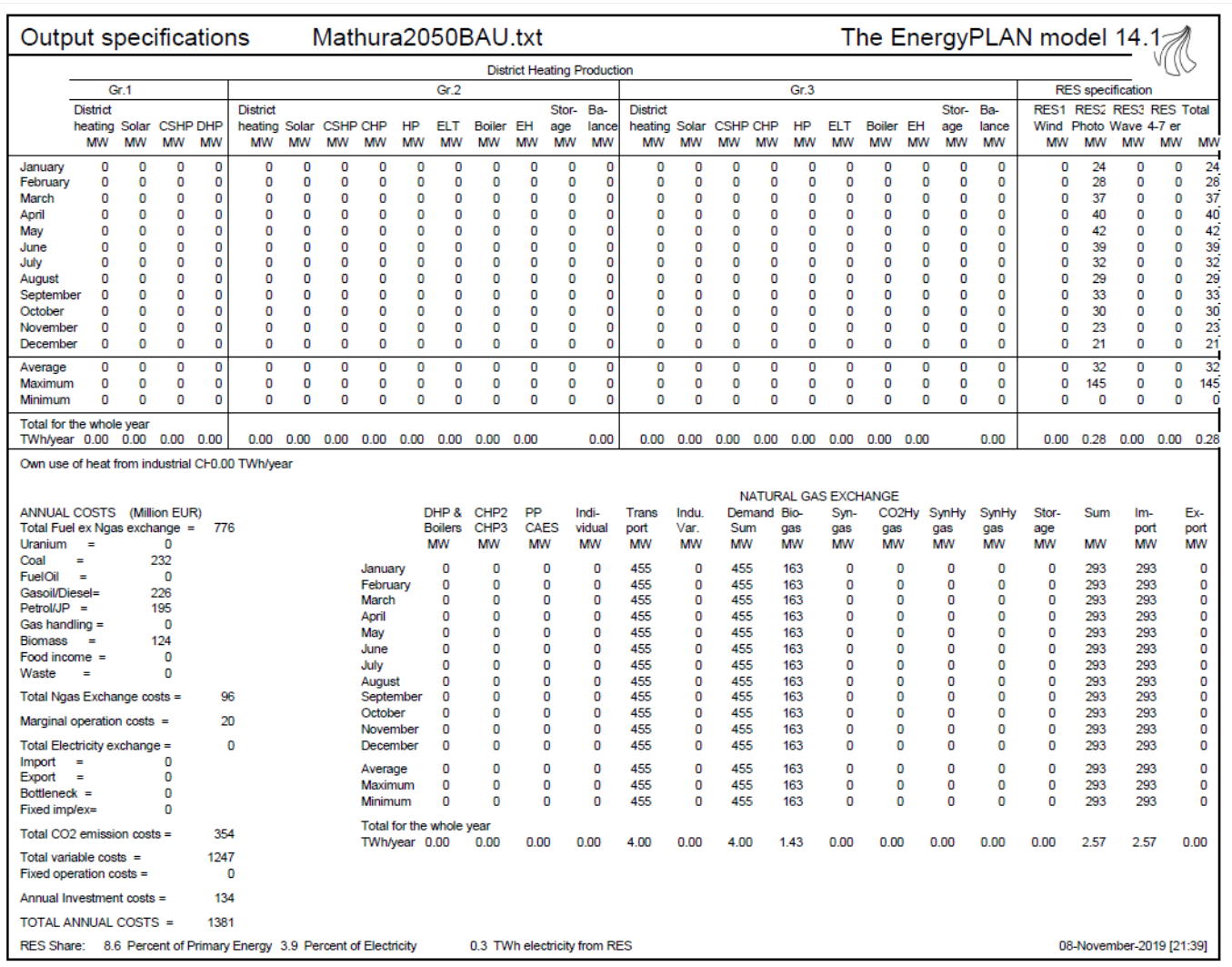




\section{C.4. Mathura Energy Transition}

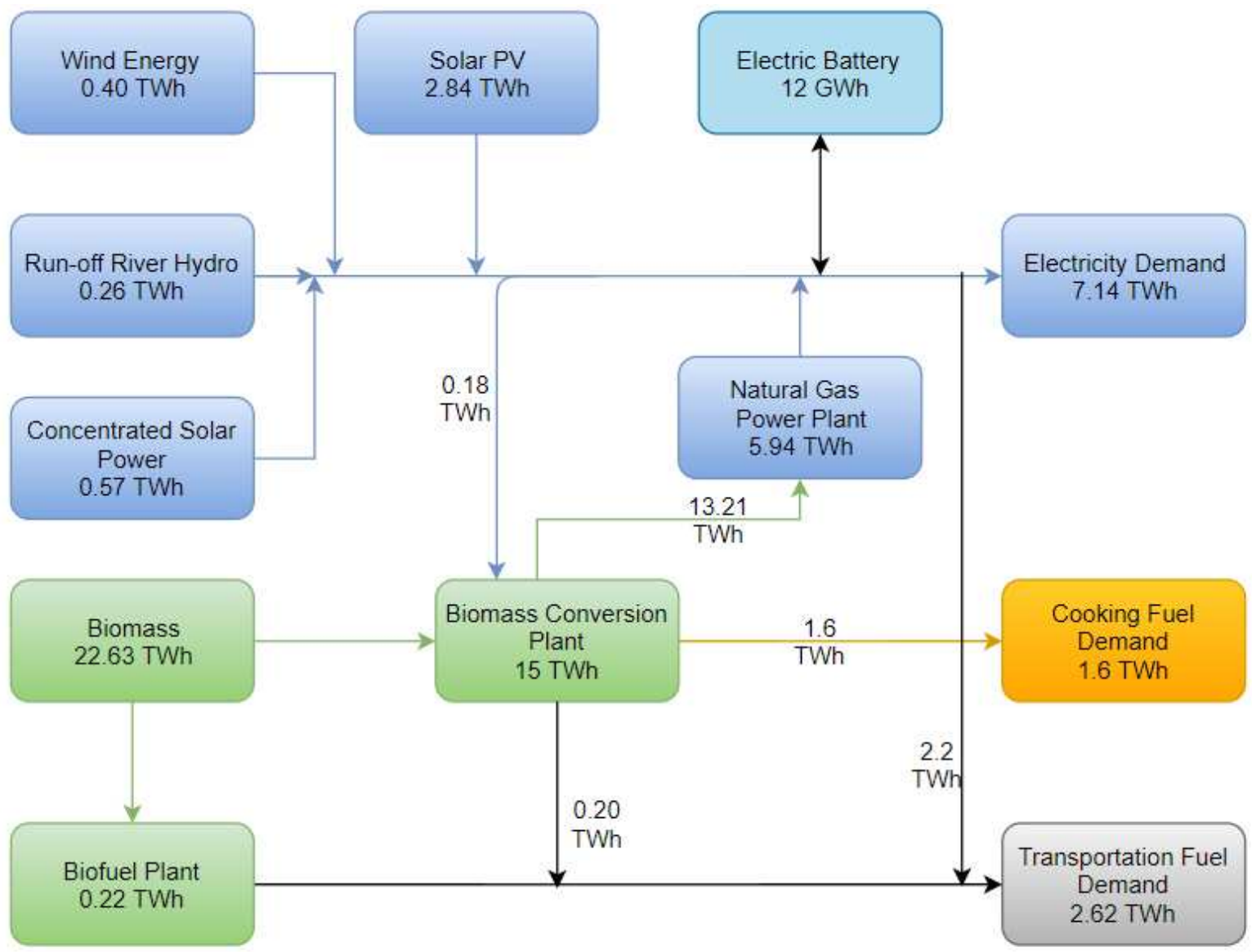

Figure 4: Energy Flow Chart for Mathura Energy Transition Scenario 2050 


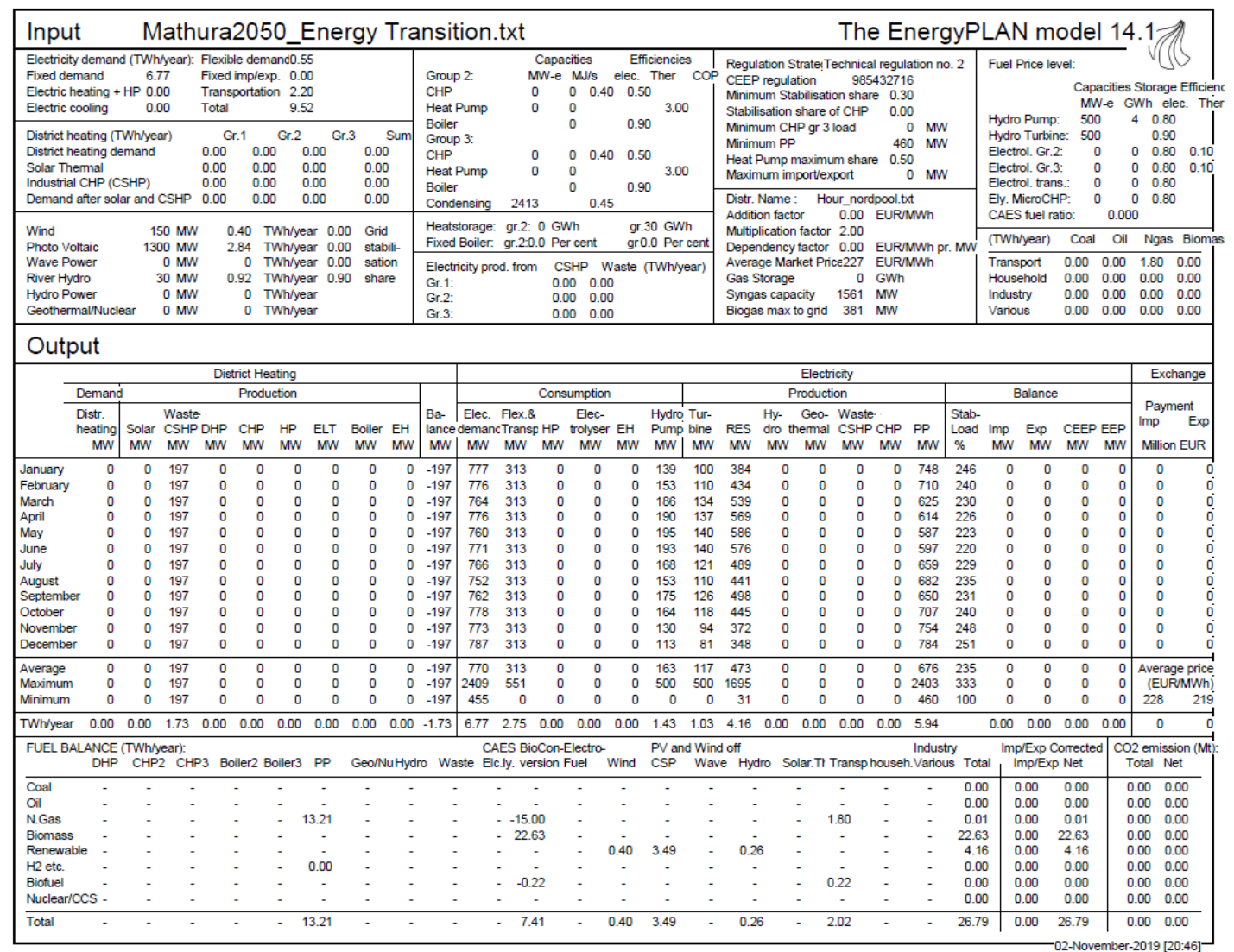

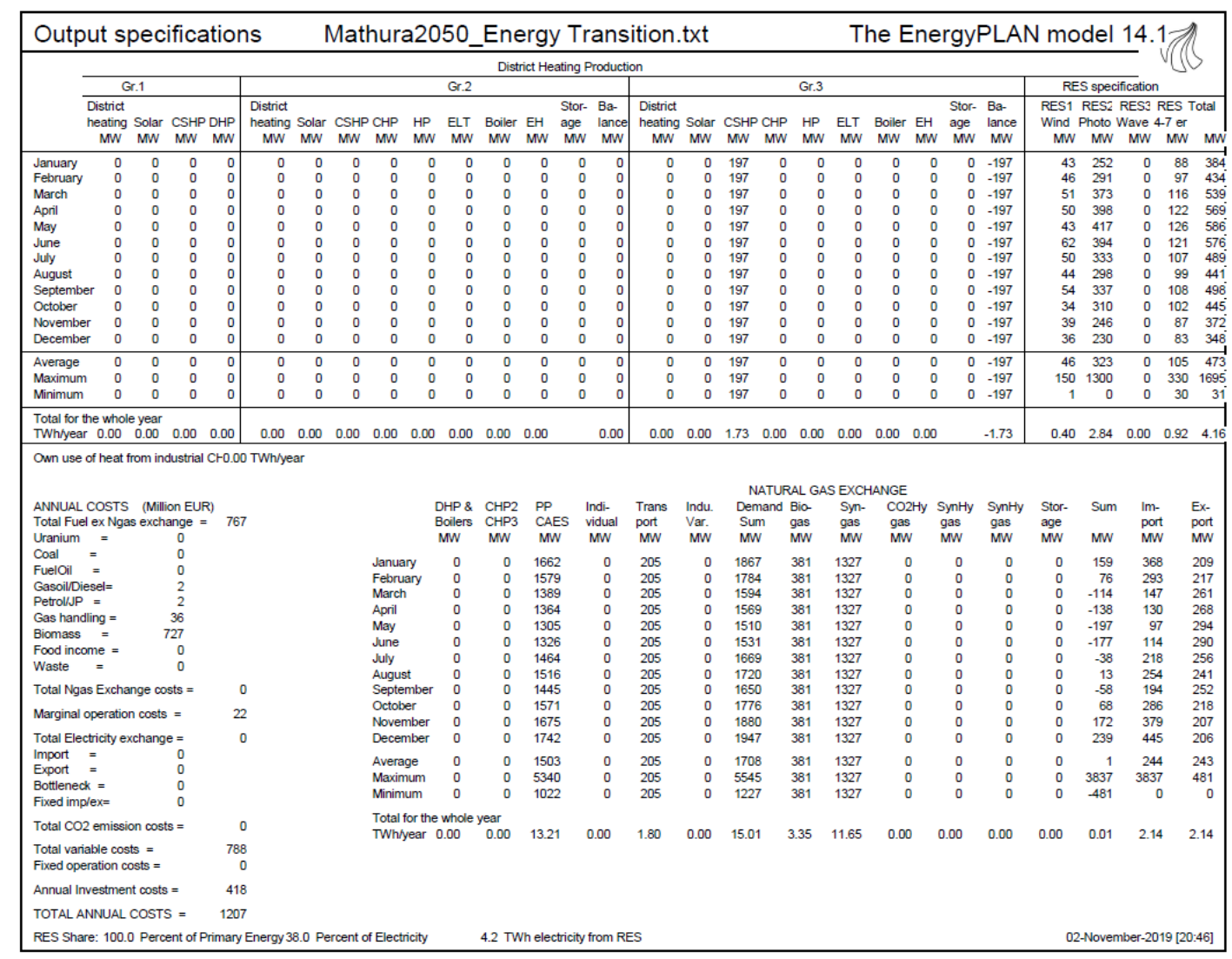




\section{Declarations}

\section{Availability of data}

All data generated or analysed during this study are included in this published article [and its supplementary information files].

\section{Competing Interests}

The authors declare that they have no competing interests.

Funding

No funding involved

Author's contributions

SJ conducted the research and wrote the first draft of the paper

MA and AM supervised the research and the first draft of the paper

MA edited the paper into the text submitted

\section{Acknowledgements}

We acknowledge the time and effort of the editor and the reviewers in considering the paper for publication. 


\section{References}

60 Second guide to the Global North/South Divide. (n.d.). Retrieved from Royal Geographical Society: www.rgs.org

Akizu, O., Urkidi, L., Bueno, G., Lago, R., Barcena, I., Mantxo, M., . . Lopez-Guede, J. M. (2017). Tracing the emerging energy transitions in the Global North and the Global South. International journal of bydrogen energy 42, 18045 - 18063.

Akkaya, E., \& Demir, A. (2009). Energy Content Estimation Of Municipal Solid Waste By Multiple Regression Analysis . 5th International Advanced Technologies Symposium (LATS'09),.

Arto, I., Capellan-Perez, I., Lago, R., Bueno, G., \& Bermejo, R. (2016). The energy requirements of a developed world. . Energy Sustain Dev, 1-13.

Beurskens, P. R. (2016). Programma Nieune Energie Provincie Overijssel 2017 - 2023. ECN.

Biogas. (2019). Retrieved from Vikaspedia: http://vikaspedia.in/energy/energy-production/bioenergy/biogas

Bisaglia, C., Brambilla, M., Cutini, M., Bortolotti, A., Rota, G., Minuti, G., \& Sargiani, R. (2018). Reusing Pruning Residues for Thermal Energy Production: A Mobile App to Match Biomass Availability with the Heating Energy Balance of Agro-Industrial Buildings. theSustainability2018,10.

Bruce, N., Perez-Padilla, R., \& Albalak, R. (2000). Indoor air pollution in developing countries: A major environmental and public health challenge. Bulletin of the World Health Organization Volume 78, Issue 9, 1078-1092.

Collins, P. H. (2000). Black Feminist Thought: Knowledge, Consciousness, and the Politics. New York: Routledge.

David W. Patterson, P. F. (n.d.). Landowner's Guide to Determining Weight of Standing Hardwood Trees. Agriculture and Natural Resources, University of Arkansas.

Day, R., Walker, G., \& Simcock, N. (2016). Conceptualising energy use and energy poverty using a capabilities framework. Energy Policy, 255-264.

De Paula, S., \& Dymski, G. :. (2005). Reimagining growth: Towards a renewal of development theory. Zed Books.

DTE Staff. (2019, January 20). Renewable energy in India: why rooftop remains the most untapped solar source. Retrieved from Down to Earth: https://www.downtoearth.org.in/news/energy/renewableenergy-in-india-why-rooftop-remains-the-most-untapped-solar-source-62873

EnergyPLAN. (2017). Energy PLAN: Advanced Energy Systems Analysis Computer Model (Documentation Version 14). EnergyPLAN.

Eriksen, T. H. (2015). What's wrong with the Global North and Global South? In Concepts of the Global South. Cologne, Germany, Germany: Global South Studies Center Cologne. 
Gravalos, I., Xyradakis, P., Kateris, D., Gialamas, T., Bartzialis, D., \& Giannoulis, K. (2016). An Experimental Determination of Gross Calorific Value of Different Agroforestry Species and Bio-Based Industry Residues. Natural Resources 07(01), 57-68.

Hoornweg, D., \& Bhada-Tata, P. (2012). Waste Generation. In What a Waste : A Global Review of Solid Waste Management (pp. 8-13). Washington, DC: World Bank.

Hoppe, T., Dijk, A. K.-v., \& Arentsen, M. (2011). Governance of bio-energy: The case of Overijssel. Resilient Societies Conference, IGS, University of Twente. Enschede.

Howden-Chapman, P., V., H., C., R., O., K., B., \& Lloyd, L. (2012). Tackling cold housing and fuel poverty in New Zealand: a review of policies, research, and health impacts. Energy Policy 49, 134-142.

Iqbal, Y., Lewandowski, I., Weinreich, A., Wippel, B., Pforte, B., Hadai, O., . . Peters, D. (2016). Maximising the yield of biomass from residues of agricultural crops and biomass from forestry. European Comission.

Kemmler, A., \& Spreng, D. (2007). Energy indicators for tracking sustainability in developing countries. Energy Policy, 35, 2466-2480.

Kuria, J., \& Maringa, M. (2008). Developing Simple Procedures For Selecting, Sizing, Scheduling Of Materials and Costing Of Small Bio - Gas Units. International Journal for Service Learning in Engineering, 9-40.

Land cover and land use. (2018). European Commission. Retrieved from https:/ /ec.europa.eu/agriculture/sites/agriculture/files/statistics/facts-figures/land-coveruse.pdf

Laurie, N., Andolina, R., \& Radcliffe, S. (2005). Ethnodevelopment: Social movements, creating experts and professionalising indigenous knowledge in Ecuador. Antipode 37, 470-496.

Li, D. M. (2018, June 28). World Energy 2018-2050: World Energy Annual Report (Part 1). Retrieved from Peak Oil Barrel: http:// peakoilbarrel.com/world-energy-2018-2050-world-energyannual-report-part-1/

Ming'ate, F. L. (2015). The Global South: What does it mean to Kenya? In Concepts of the Global South. Cologne, Germany: Global South Studies Center Cologne.

Persoon, E., Luitjens, S., Boonstra, L., \& Moerkerken., P. v. (2017). The future Dutch full carbon-free energy system. KIVI Engineering Society.

Petrova, S., Gentile, M., Mäkinen, I., \& Bouzarovski, S. (2013). Perceptions of thermal comfort and housing quality : exploring the microgeographies of energy poverty in Stakhanov,Ukraine. Environmental Plan 52, 1240-1257.

Pike, A., Rodríguez-Pose, A., \& Tomaney, J. (2014). Local and regional development in the Global North and South. Progress in Development Studies 14, 21-30. 
Province of Overijssel. (2019, January). Retrieved from City Population:

https://www.citypopulation.de/php/netherlands-admin.php?adm1id=NL21

Purcell, L. (2015). Tree Pruning Essentials. Purdue: Forestry and Natural Resources.

Rana, M. M. (2009). Sustainable city in the global North and South: Goal or principle? Management of Environmental Quality An International Journal, 506-521.

Savage, V. (2006). Ecology matters: sustainable development in Southeast Asia. Sustainability Science, Vol. 1 No. 1, 37-63.

Sen, A. (2014, August 23). Global Warming Is Just One of Many Environmental Threats That Demand Our Attention. Retrieved from The New Republic:

https://newrepublic.com/article/118969/environmentalists-obsess-about-global-warmingignore-poor-countries

Sørensen, B. (2012). A History of Energy : Northern Europe from the Stone Age to the Present Day. Abingdon: Earthscan.

Thomson, H., \& Snell, C. (2013). Quantifying the prevalence of fuel poverty across the European Union. Energy Policy 52, 563-572.

Tree Spacing Calculator. (2000). Retrieved from Tree Plantation: https://www.treeplantation.com/treespacing-calculator.html

Tree species that are common in the Dutch woods. (n.d.). Retrieved from Bomengids: https://www.bomengids.nl/uk/bosbomen.html

Vodde, G. M. (2006). Forests and Forestry in The Netherlands. Forests and forestry in European Union Countries. 


\section{Figures}

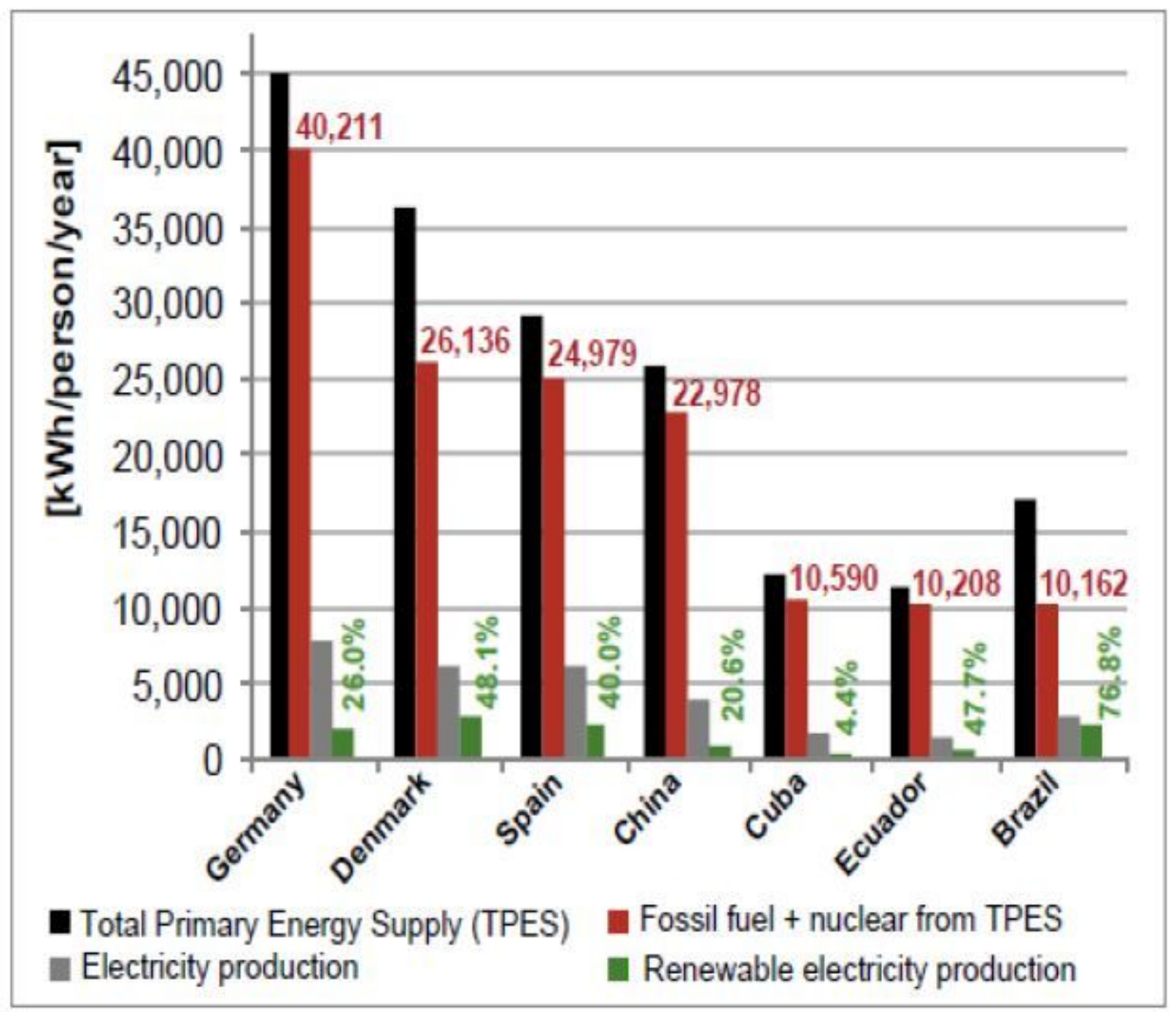

Figure 1

Primary Energy Supply per person every year in different countries signifying the differences in the GN and GS. 


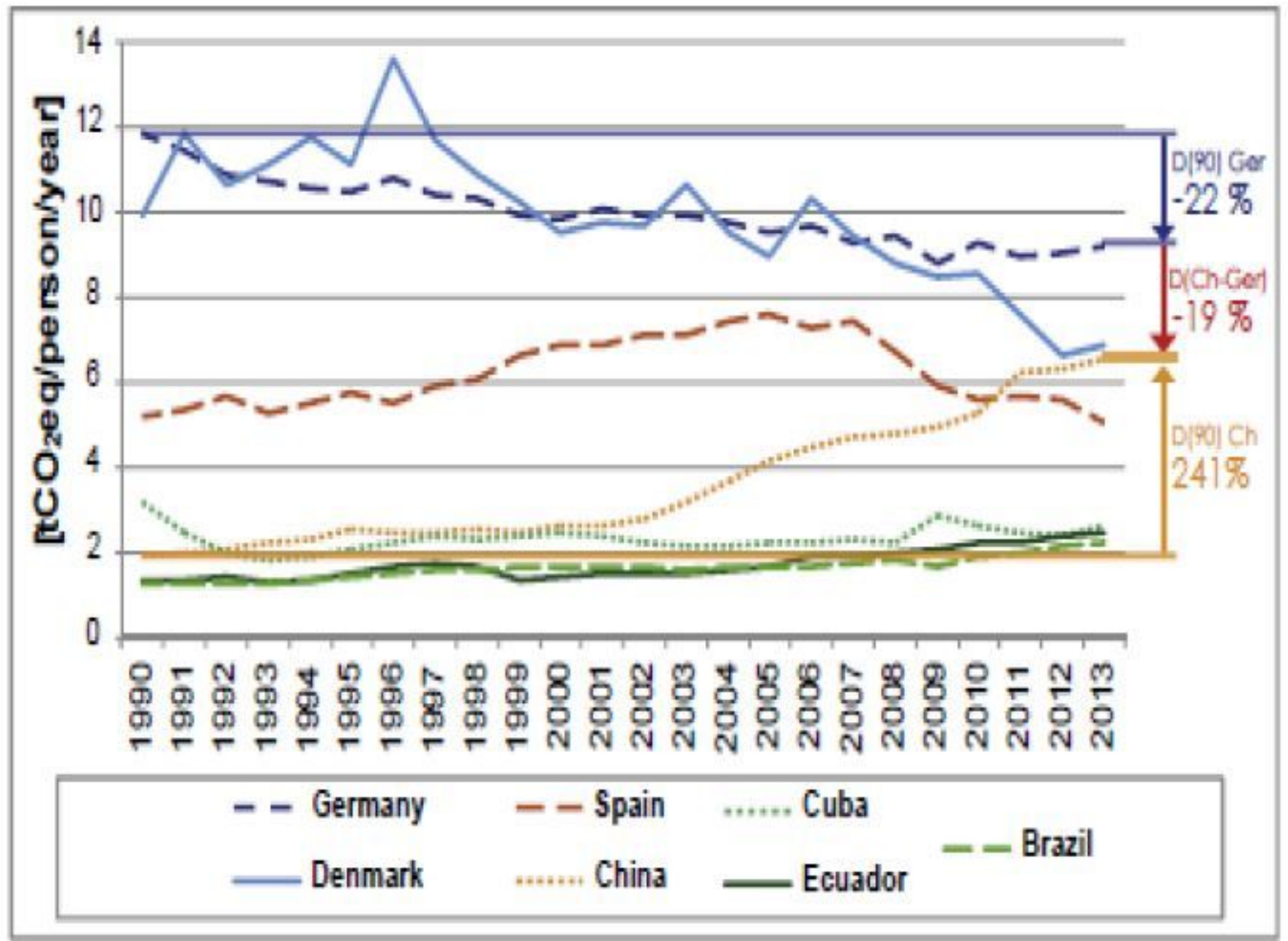

Figure 2

CO2eq emission from fuel consumption for the energy supply of globalized countries.
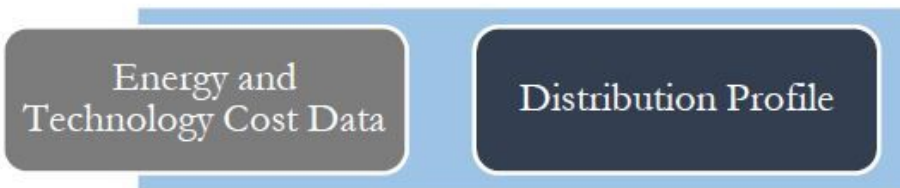
Reorganization of data
to input into the
EnergyPLAN tool
Entering the Data into
EnergyPLAN

Figure 3

Process Flow for Data to be utilized in energyPLAN 